\title{
Development of a Health-Related Quality of Life Questionnaire (HRQL) for patients with Extremity Soft Tissue Infections (ESTI) Aric J Storck ${ }^{1}$, Kevin B Laupland*2,3,4, Ronald R Read ${ }^{2,4}$, Manuel W Mah2,4, John M Gill ${ }^{2,4}$, Deborah Nevett ${ }^{4}$ and Thomas J Louie ${ }^{2,4}$
}

Address: ${ }^{1}$ Department of Emergency Medicine, Calgary Health Region, Calgary, Alberta, Canada, ${ }^{2}$ Department of Medicine, Calgary Health Region and University of Calgary, Calgary Alberta, Canada, ${ }^{3}$ Department of Community Health Sciences, University of Calgary, Calgary, Alberta, Canada and ${ }^{4}$ Home Parenteral Therapy Program, Peter Lougheed Centre, Calgary, Alberta, Canada

Email: Aric J Storck - astorck@ucalgary.ca; Kevin B Laupland* - kevin.laupland@calgaryhealthregion.ca; Ronald R Read - ron.read@calgaryhealthregion.ca; Manuel W Mah - manuel.mah@calgaryhealthregion.ca; John M Gill - john.gill@calgaryhealthregion.ca; Deborah Nevett - deb.nevitt@calgaryhealthregion.ca; Thomas J Louie - thomas.louie@calgaryhealthregion.ca

* Corresponding author

Published: II October 2006

BMC Infectious Diseases 2006, 6:148 doi:10.1 I86/147|-2334-6-148
Received: 25 May 2006

Accepted: II October 2006

This article is available from: http://www.biomedcentral.com/I47I-2334/6//48

(c) 2006 Storck et al; licensee BioMed Central Ltd.

This is an Open Access article distributed under the terms of the Creative Commons Attribution License (http://creativecommons.org/licenses/by/2.0), which permits unrestricted use, distribution, and reproduction in any medium, provided the original work is properly cited.

\begin{abstract}
Background: Past clinical trials of antimicrobial treatment in soft tissue infections have focused on non-standardized clinical and physiological outcome variables, and have not considered the subjective experience of patients. The objective of this study was to develop a health-related quality of life questionnaire (HRQL) for patients with extremity soft tissue infections (ESTI) for future use in clinical trials.
\end{abstract}

Methods: The design of this study followed published guidelines and included item generation, item reduction, and questionnaire preparation. Study subjects were consenting English-speaking adults with acute ESTI requiring prescription of at least two days of outpatient intravenous antibiotic therapy.

Results: A list of 49 items that adversely impact the quality of life of patients with ESTI was generated by literature review, informal health professional feedback, and semi-structured interviews with twenty patients. A listing of these items was then administered to 95 patients to determine their relative importance on quality of life. A questionnaire was prepared that included the twenty most important items with a 5-point Likert scale response. Questionnaire domains included physical symptoms, problems performing their activities of daily living, impairment of their emotional functioning, and difficulties in their social interactions as related to their ESTI. The final questionnaire was pre-tested on a further ten patients and was named the ESTI-Score.

Conclusion: The ESTI-Score is a novel instrument designed to quantify the impact of ESTI on quality of life. Future study is required to determine its validity and responsiveness before use as an outcome measure in clinical trials. 


\section{Background}

Soft tissue infections (STI) are among the most common infectious diseases requiring antibiotic treatment $[1,2]$. Despite their prevalence and importance, the optimal treatment of STI's has not been well defined and considerable practice variation exists with respect to their management. Although a wide variety of different antibiotic classes, doses, durations, and methods of delivery have been compared in clinical trials, few studies have shown superiority of a given treatment [3]. While this may represent true clinical equipoise, it may also at least in part reflect the insensitivity of outcome measures used. These most commonly are non-standardized, disease-oriented, physician assessments that may not adequately assess the effect of therapy on the patient's subjective treatment responses.

The use of Health Related Quality of Life (HRQL) scales have been developed and demonstrated to be useful and valid primary outcome measures in clinical trials in a number of diseases not limited to asthma, rhinoconjunctivitis, polycystic ovarian syndrome, and sleep apnea [48]. Although quality of life measures have been developed for chronic skin diseases, no HRQL clinical instrument has been previously developed for acute extremity soft tissue infections (ESTI) $[9,10]$. The objective of this study was therefore to develop a disease-specific instrument to measure the HRQL in patients with ESTI for future use in clinical trials.

\section{Methods}

The study methodology followed previously published guidelines for development of HRQL instruments $[11,12]$. This process included item generation, item reduction, questionnaire preparation, and questionnaire pre-testing. The study protocol was reviewed and approved by the Conjoint Health Research Ethics Board of the University of Calgary. All subjects provided written informed consent prior to participation. In addition to questionnaire specific data, information was also collected on patient demographics, co-morbidities, and the treatments prescribed.

\section{Study subjects}

Patients with ESTI were enrolled from the Home Parenteral Therapy Program (HPTP) clinic at the Peter Lougheed Centre, Calgary, Alberta, Canada [13]. The HPTP is an ambulatory clinic that serves patients with a variety of infectious diseases requiring parenteral antimicrobial therapy. It is attended by fully certified infectious disease specialists. Between November 2003 and May 2005 a convenience sample of patients was screened for inclusion in the study. Patients were eligible for the study if they met all of the following: 1) age at least eighteen at the time of enrollment, 2) a diagnosis of ESTI made by an
HPTP physician, and 3) judged to require two or more days of parenteral antibiotics by the HPTP physician. Patients were excluded if they had any of the following: 1 ) a chronic ulcer with no evidence of acute infection, 2) inability to speak and read English, 3) they were expected to have poor adherence to the study protocol, or 4) they were ineligible for the outpatient HPTP clinic (eg: admitted to hospital). Patients were otherwise included in the study irrespective of the severity of their illness, their co-morbidities, or specific treatment regimen prescribed.

\section{Item generation}

The goal of this phase was to identify all possible items that might adversely impact the quality of life of patients with ESTI. These items were identified using four standard methods: 1) a review of the published literature on the clinical features of soft tissue infections, 2) a review of HRQL scales in other medical conditions, 3) semi-structured interviews with a group of patients, and 4) the collective experience of the study investigators and clinic staff. The patient interviews were performed by trained research nurses and took approximately 30 minutes. The interview used open-ended questions to identify all possible areas of dysfunction (including physical symptoms, activities of daily living, social and emotional well being) that might be adversely affected by their ESTI.

\section{Item reduction}

The purpose of this phase was to identify the most important items for patients with ESTI. Study participants independently completed a questionnaire containing the items identified in the item generation phase. They were asked to identify which of the items were problems for them. For items identified as being a problem, they were asked to rate how important it was on a 5-point Likert scale (ranging 1, not very important, to 5, extremely important). The overall importance of each item was determined by calculating its frequency importance product (FIP). This was done by multiplying the frequency that a particular item was reported as a problem by the mean importance assigned to it [8].

\section{Final questionnaire preparation}

The twenty items with the highest FIPs were incorporated into the final questionnaire. It was pre-tested on another group of consenting patients to ensure that it was free of grammatical errors and that individual items and the overall format were easily understood.

\section{Statistical considerations}

Sample sizes were chosen a priori to be 20 patients for item generation and 100 patients for item reduction based on the guidelines of Kirshner and Guyatt [12]. All statistical analysis was performed using Stata 8.0 (StataCorp, College Station, Texas). Medians with interquartile ranges 
(IQR) were used to describe non-normally distributed variables and means with standard deviations (SD) for normally distributed variables. Group means were compared using Fisher's t-test. A p-value $<0.05$ was deemed to represent statistical significance.

\section{Results \\ Item generation}

Through interviews with twenty consenting patients with ESTI, a review of the relevant literature, and the collective experience of the study investigators, a list of 49 items was generated for inclusion in the item reduction questionnaire and these are shown in Table 1.

\section{Item reduction}

Ninety-five patients were ultimately included in this stage. One hundred and three patients were initially enrolled but eight patients were subsequently excluded because they did not maintain enrollment criteria. In six patients the reason for exclusion was an alternate final diagnosis [osteomyelitis (three); gout (two); deep venous thrombosis (one)]. One patient was subsequently excluded because he was recognized later to be seventeen years of age at the time of enrollment. One patient was inadvertently enrolled into the study on two separate occasions and as such only the first presentation was analyzed.

The characteristics of the 95 analyzed patients and their infections are summarized in Table 2. The patients were most commonly middle-aged men with uncomplicated cellulitis who were referred from the emergency department.

The overall importance of each of the items was calculated as frequency-importance-products and reported in Table 1 .

\section{Final questionnaire preparation}

The twenty highest ranked items identified in item reduction (Table 1) were grouped into domains and included in the final questionnaire. They were presented in a similar fashion as in the item reduction questionnaire. These twenty items represent each of the HRQL domains including symptoms (seven items), daily functioning (seven items), emotional functioning (five items), and social interactions (one item). The final questionnaire was pretested on a group of ten patients. After filling out the survey independently they reviewed it with one of the study investigators. No patient reported any difficulty in completing the questionnaire or interpreting the items.

\section{The ESTI Score}

The final ESTI-Score for a patient was calculated by adding their scores for each item. The minimum and maximum possible scores are zero and one hundred respectively. The
ESTI-Score was post hoc calculated for each of the patients in the item reduction cohort. The mean ESTI-Score was $47.2 \pm 21.1$ points and their distribution is shown in Figure 1. No significant differences in mean scores were observed overall between men and women, cellulitis versus other ESTI, or upper versus lower extremity site of infection.

\section{Discussion}

We report the development of the first HRQL indicator for use in patients with ESTI. This tool was developed using established methodological guidelines and included a diverse cohort of ambulatory adult patients with a variety of soft tissue infections. It incorporated items representing multiple areas of quality of life impairment including physical symptoms, activities of daily living, emotional and social functioning. When pre-tested on another group of patients the final questionnaire was found to be straightforward and easy to independently complete in less than 10 minutes. In a post hoc analysis, of our patient cohort, the ESTI-Score produced a broad range of nearnormally distributed values, potentially reflecting the range of severity of ESTI in our patients.

Clinical trials of ESTI reported to date have largely used a variety of disease-oriented outcome measures. Often a categorical assessment such as "cure" or "failure", "resolution of infection", or "improvement" is assigned by a study investigator based on a non-standardized clinical assessment [14-22]. Another approach has been to use "microbiological eradication" or "microbiological persistence" as an outcome measure [16,18-20]. The utility of such an outcome measure is hampered by the fact that the majority of soft tissue infections are culture negative or will rapidly become culture negative even if sub-optimally managed $[23,24]$. Others have attempted to quantify improvement based on measurements of areas of inflammation although this has not been validated and may not be closely related to patients' symptoms [25]. While patients' subjective experiences are often included in a composite clinical assessment by a physician or study investigator, the use of a HRQL measure allows actual quantification of these experiences and the effect of treatment.

Generic health measures such as the Medical Outcomes Study 36-Item Short-Form Health Survey (SF-36) [26], and the Nottingham Health Profile (NHP) [27], have been developed to measure quality of life in a broad range of illnesses. They may not, however, be able to detect the subtle effects on quality of life specific to a particular disease. Specific HRQL scales have been developed and validated for other diseases and have been used as outcome measures in clinical trials [4-8]. Tools, such as the "Skindex," have been developed to evaluate the HRQL in 
Table I: Items included in the Item Reduction Questionnaire. Overall importance of each item as measured by the Frequency Importance Product.

\begin{tabular}{|c|c|c|c|}
\hline Item & Frequency* & Mean importance+ & Overall importance++ \\
\hline \multicolumn{4}{|l|}{ Symptoms } \\
\hline Pain & 0.95 & 3.69 & 3.49 \\
\hline Fever & 0.42 & 3.23 & 1.36 \\
\hline Chills & 0.51 & 3.06 & 1.55 \\
\hline Sweating & 0.43 & 2.84 & 1.23 \\
\hline Loss of appetite & 0.46 & 3.07 & 1.42 \\
\hline Nausea & 0.27 & 2.63 & 0.72 \\
\hline Numbness & 0.40 & 2.74 & 1.10 \\
\hline Swelling & 0.92 & 3.88 & 3.56 \\
\hline Blistering & 0.28 & 3.28 & 0.93 \\
\hline Fatigue & 0.54 & 3.40 & 1.83 \\
\hline Trouble moving & 0.75 & 3.47 & 2.59 \\
\hline Stiffness & 0.60 & 3.28 & 1.97 \\
\hline Soreness & 0.92 & 3.76 & 3.44 \\
\hline Pressure & 0.66 & 3.43 & 2.28 \\
\hline Throbbing & 0.61 & 3.36 & 2.05 \\
\hline Streaking & 0.20 & 2.81 & 0.56 \\
\hline Discomfort in a distant body part & 0.40 & 3.36 & 1.34 \\
\hline Discomfort caused by treatment of your infection & 0.33 & 2.74 & 0.89 \\
\hline \multicolumn{4}{|l|}{ Daily Functioning } \\
\hline Doing your job & 0.79 & 3.96 & 3.13 \\
\hline Walking & 0.59 & 3.48 & 2.05 \\
\hline Bathing & 0.62 & 3.45 & 2.14 \\
\hline Using the toilet & 0.38 & 2.97 & 1.13 \\
\hline Driving & 0.51 & 3.27 & 1.65 \\
\hline Changing clothes & 0.64 & 2.98 & 1.92 \\
\hline Hobbies & 0.51 & 3.10 & 1.57 \\
\hline Earning an income & 0.54 & 4.08 & 2.19 \\
\hline Exercising & 0.66 & 3.20 & 2.12 \\
\hline Falling asleep & 0.62 & 3.53 & 2.19 \\
\hline Traveling & 0.38 & 3.03 & 1.15 \\
\hline \multicolumn{4}{|l|}{ Emotional Functioning } \\
\hline Frustrated & 0.68 & 3.46 & 2.37 \\
\hline Impatient & 0.46 & 3.33 & 1.54 \\
\hline Irritable & 0.57 & 3.09 & 1.76 \\
\hline Angry & 0.28 & 3.27 & 0.93 \\
\hline Disappointed & 0.61 & 3.18 & 1.94 \\
\hline Afraid & 0.47 & 3.27 & 1.55 \\
\hline Annoyed & 0.55 & 3.50 & 1.92 \\
\hline Embarrassed & 0.31 & 2.77 & 0.85 \\
\hline Miserable & 0.34 & 3.26 & 1.10 \\
\hline Depressed & 0.28 & 2.67 & 0.76 \\
\hline Sad & 0.34 & 2.75 & 0.93 \\
\hline Stressed & 0.51 & 2.98 & 1.51 \\
\hline Exhausted & 0.58 & 3.38 & 1.96 \\
\hline Inconvenienced & 0.75 & 3.41 & 2.55 \\
\hline \multicolumn{4}{|l|}{ Social Interactions } \\
\hline Difficulty socializing because your infection is "disfiguring" & 0.19 & 2.57 & 0.49 \\
\hline Difficulty getting out of the house & 0.41 & 3.21 & 1.32 \\
\hline Less desire to socialize than usual & 0.40 & 3.11 & 1.24 \\
\hline You are inconveniencing your friends and family & 0.56 & 3.37 & 1.88 \\
\hline Difficulty being physically intimate with your partner & 0.36 & 3.56 & 1.27 \\
\hline Difficult being emotionally intimate with your partner & 0.24 & 3.33 & 0.81 \\
\hline
\end{tabular}

*Frequency of study participants reporting item as a problem (maximum $=1.0$ )

+ Mean importance assigned to item if reported as a problem (maximum $=5.0$ )

++ Frequency importance product (frequency $\times$ mean importance) (maximum $=5.0$ )

NB: The twenty highest ranking items are in bold font and were included in the final questionnaire and calculation of the ESTI score. 
Table 2: Characteristics of 95 patients with ESTI included in the item reduction phase.

\begin{tabular}{ll}
\hline Characteristic & Number \\
\hline Mean years of age (SD) & $47.5(14.3)$ \\
Male gender (\%) & $74(77.9)$ \\
Referral location (\%) & $86(90.5)$ \\
$\quad$ Emergency Department & $9(9.5)$ \\
Other & $10(10.5)$ \\
Comorbidities (\%) & $7(7.3)$ \\
$\quad$ Diabetes Mellitus & $10(10.5)$ \\
Peripheral Vascular Disease & $5(5.2)$ \\
Immunosuppression & $3(3.2)$ \\
$\quad$ Animal Bites & \\
Post-surgical & $77(81.1)$ \\
Primary diagnosis (\%) & $12(12.6)$ \\
$\quad$ Cellulitis & $3(3.2)$ \\
Septic bursitis & $3(3.2)$ \\
Septic tenosynovitis & \\
Abscess & $36(37.9)$ \\
Location of ESTI (\%) & $59(62.1)$ \\
$\quad$ Upper extremity & $4(2-7)$ \\
$\quad$ Lower extremity & $4(3-6)$ \\
Median duration of symptoms at time of survey (interquartile range) & $14(11-16)$ \\
Median days of intravenous antibiotics (interquartile range) & \\
Median days total antibiotics (interquartile range) & \\
\hline
\end{tabular}

chronic dermatologic conditions but are not applicable to acute soft tissue infections $[9,10]$. The ESTI-Score represents the first standardized clinical instrument to measure the areas of HRQL impairment important to patients with ESTI.

As a result of the ESTI-Score being developed using a cohort of patients, it does have face and content validity. However, there are a number of limitations of the current study. First, it requires further prospective assessment in another cohort of ESTI patients prior to being used as a

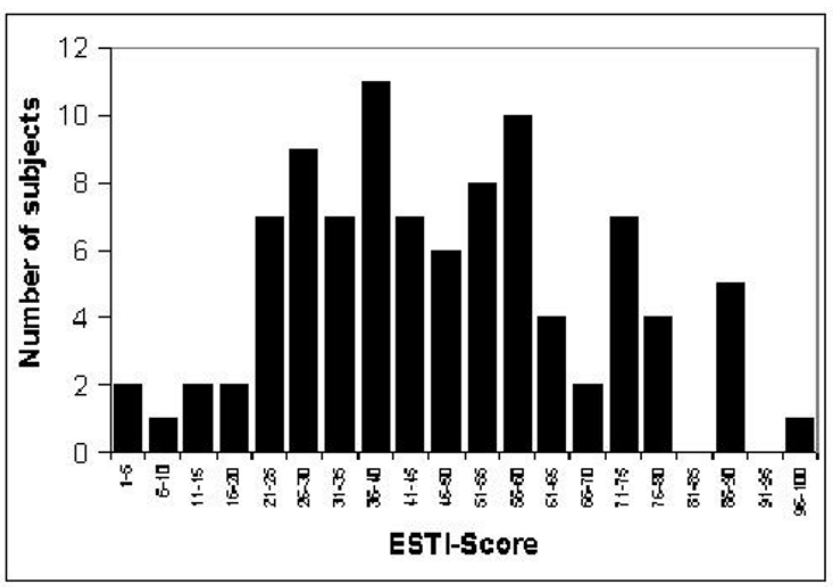

\section{Figure I}

Distribution of ESTI-Scores calculated post hoc among 95 patients included in the item reduction phase. primary outcome measure in clinical trials. Areas to be assessed include its reproducibility in patients with a stable disease state, its responsiveness to changes in infection severity, and its relationship to other markers of disease severity. Second, the ESTI-Score was derived from a group of North American adult patients receiving parenteral antibiotics at a single outpatient parenteral therapy clinic. Patients with mild disease were excluded based on the requirement for at least two days of parenteral therapy and only English speaking patients were studied. Whether it will be generalizable to adult patients in other outpatient settings in other regions remains to be seen. Third, while ESTI may have subsequent chronic impairment on quality of life, they typically are acute conditions that resolve over weeks or months and in most cases will not have a major effect on an individual's quality of life during their lifetime. The ESTI-Score may therefore represent more of an acute comprehensive disease severity index than a traditional measure of quality of life.

\section{Conclusion}

We report the development of the ESTI-Score that is designed to quantify patients subjective experiences associated with having an ESTI. Future studies are needed to validate this HRQL instrument in another cohort of adult ESTI patients so that it may be used as an important outcome measure in future clinical trials evaluating management strategies for ESTI.

\section{Abbreviations}

Extremity Soft Tissue Infections (ESTI) 
Frequency importance product (FIP)

Health-Related Quality of Life Questionnaire (HRQL)

Home Parenteral Therapy Program (HPTP)

Interquartile range (IQR)

Medical Outcomes Study 36-Item Short-Form Health Survey (SF-36)

Nottingham Health Profile (NHP)

Soft tissue infections (STI)

\section{Competing interests}

None of the authors have personal, professional, or financial conflicts of interest that would influence the conduct or reporting of this study.

\section{Authors' contributions}

AJS collected data, analyzed results, and drafted the manuscript. KL conceived and designed the study, enrolled patients, analyzed data, and contributed to the manuscript drafting. RRR, MWM, JMG, DN, and TJL enrolled patients and collected data. All authors contributed to revision of and approval of the final manuscript.

\section{Acknowledgements}

We thank Drs. Ward Flemons and H. Dele Davies for their input and advice regarding the design of this study, Sandra Vaz-Gonsalvez and Brendan Byrne for assistance with patient interviews, and Lisa Wilson and the HPTP nurses for administrative assistance and support of the study. This study was funded by an unrestricted educational grant from Bristol-Myers Squibb Canada. The author's had complete autonomy in the design and conduct of the study and the decision to publish.

\section{References}

I. Gottlieb T, Atkins BL, Shaw DR: 7: Soft tissue, bone and joint infections. Med J Aust 2002, I76:609-6I5.

2. Stulberg DL, Penrod MA, Blatny RA: Common bacterial skin infections. Am Fam Physician 2002, 66: I 19-124.

3. Sharpe JN, Shively EH, Polk HCJ: Clinical and economic outcomes of oral linezolid versus intravenous vancomycin in the treatment of MRSA-complicated, lower-extremity skin and soft-tissue infections caused by methicillin-resistant Staphylococcus aureus. Am J Surg 2005, 189:425-428.

4. Juniper EF, Guyatt GH, Epstein RS, Ferrie PJ, Jaeschke R, Hiller TK Evaluation of impairment of health related quality of life in asthma: development of a questionnaire for use in clinical trials. Thorax 1992, 47(2):76-83.

5. Guyatt GH, Naylor CD, Juniper E, Heyland DK, Jaeschke R, Cook DJ: Users' guides to the medical literature. XII. How to use articles about health-related quality of life. Evidence-Based Medicine Working Group. Jama 1997, 277: 1232-1237.

6. Juniper EF, Guyatt GH, Epstein RS, Ferrie PJ, Jaeschke R, Hiller TK Evaluation of impairment of health related quality of life in asthma: development of a questionnaire for use in clinical trials. Thorax 1992, 47:76-83.

7. Juniper EF, Guyatt GH: Development and testing of a new measure of health status for clinical trials in rhinoconjunctivitis. Clin Exp Allergy 1991, 2 1:77-83.
8. Cronin L, Guyatt G, Griffith L, Wong E, Azziz R, Futterweit W, Cook $D$, Dunaif A: Development of a health-related quality-of-life questionnaire (PCOSQ) for women with polycystic ovary syndrome (PCOS). J Clin Endocrinol Metab I998, 83: I 976- I 987.

9. Flemons WW, Reimer MA: Development of a disease-specific health-related quality of life questionnaire for sleep apnea. Am J Respir Crit Care Med 1998, I 58:494-503.

10. Chren MM, Lasek RJ, Quinn LM, Mostow EN, Zyzanski SJ: Skindex, a quality-of-life measure for patients with skin disease: reliability, validity, and responsiveness. J Invest Dermatol 1996 , 1 07:707-7|3.

II. Anderson RT, Rajagopalan R: Development and validation of a quality of life instrument for cutaneous diseases. J Am Acad Dermatol 1997, 37:41-50.

12. Guyatt GH, Bombardier C, Tugwell PX: Measuring disease-specific quality of life in clinical trials. Cmaj 1986, I34:889-895.

13. Kirshner B, Guyatt G: A methodological framework for assessing health indices. I Chronic Dis 1985, 38:27-36.

14. Laupland KB, Gill MJ, Schenk L, Goodwin D, Davies HD: Outpatient parenteral antibiotic therapy: evolution of the Calgary adult home parenteral therapy program. Clin Invest Med 2002, 25:185-190

15. Fabian TC, File TM, Embil JM, Krige JE, Klein S, Rose A, Melnick D, Soto NE: Meropenem versus imipenem-cilastatin for the treatment of hospitalized patients with complicated skin and skin structure infections: results of a multicenter, randomized, double-blind comparative study. Surg Infect (LarChmt) 2005, 6:269-282.

16. Arbeit RD, Maki D, Tally FP, Campanaro E, Eisenstein BI: The safety and efficacy of daptomycin for the treatment of complicated skin and skin-structure infections. Clin Infect Dis 2004, 38:1673-|68|.

17. Siami FS, LaFleur BJ, Siami GA: Clinafloxacin versus piperacillin/ tazobactam in the treatment of severe skin and soft-tissue infections in adults at a Veterans Affairs medical center. Clin Ther 2002, 24:59-72.

18. Graham DR, Lucasti C, Malafaia O, Nichols RL, Holtom P, Perez NQ, McAdams A, Woods GL, Ceesay TP, Gesser R: Ertapenem once daily versus piperacillin-tazobactam 4 times per day for treatment of complicated skin and skin-structure infections in adults: results of a prospective, randomized, double-blind multicenter study. Clin Infect Dis 2002, 34: |460-|468.

19. Tarshis GA, Miskin BM, Jones TM, Champlin J, Wingert KJ, Breen JD, Brown MJ: Once-daily oral gatifloxacin versus oral levofloxacin in treatment of uncomplicated skin and soft tissue infections: double-blind, multicenter, randomized study. Antimicrob Agents Chemother 200I, 45:2358-2362.

20. Wasilewski MM, Wilson MG, Sides GD, Stotka JL: Comparative efficacy of 5 days of dirithromycin and 7 days of erythromycin in skin and soft tissue infections. J Antimicrob Chemother 2000 , 46:255-262.

21. Bucko AD, Hunt BJ, Kidd SL, Hom R: Randomized, double-blind, multicenter comparison of oral cefditoren 200 or $400 \mathrm{mg}$ BID with either cefuroxime $250 \mathrm{mg}$ BID or cefadroxil $500 \mathrm{mg}$ BID for the treatment of uncomplicated skin and skin-structure infections. Clin Ther 2002, 24:। I34- II 47.

22. Grayson ML, Gibbons GW, Habershaw GM, Freeman DV, Pomposelli $F B$, Rosenblum BI, Levin E, Karchmer AW: Use of ampicillin/sulbactam versus imipenem/cilastatin in the treatment of limbthreatening foot infections in diabetic patients. Clin Infect Dis 1994, I 8:683-693.

23. Hepburn MJ, Dooley DP, Skidmore PJ, Ellis MW, Starnes WF, Hasewinkle WC: Comparison of short-course (5 days) and standard ( 10 days) treatment for uncomplicated cellulitis. Arch Intern Med 2004, I 64: I669-1674.

24. Leppard BJ, Seal DV, Colman G, Hallas G: The value of bacteriology and serology in the diagnosis of cellulitis and erysipelas. Br J Dermatol 1985, I | 2:559-567.

25. Swartz MN: Clinical practice. Cellulitis. N Engl J Med 2004, 350:904-912

26. Brown G, Chamberlain R, Goulding J, Clarke A: Ceftriaxone versus cefazolin with probenecid for severe skin and soft tissue infections. J Emerg Med 1996, I4:547-55I.

27. Ware JEJ, Sherbourne CD: The MOS 36-item short-form health survey (SF-36). I. Conceptual framework and item selection. Med Care 1992, 30:473-483. 
28. Hunt SM, McEwen J, McKenna SP: Measuring health status: a new tool for clinicians and epidemiologists. J R Coll Gen Pract 1985, 35:185- 188 .

\section{Pre-publication history}

The pre-publication history for this paper can be accessed here:

http://www.biomedcentral.com/1471-2334/6/148/pre pub

Publish with Bio Med Central and every scientist can read your work free of charge

"BioMed Central will be the most significant development for disseminating the results of biomedical research in our lifetime. " Sir Paul Nurse, Cancer Research UK

Your research papers will be:

- available free of charge to the entire biomedical community

- peer reviewed and published immediately upon acceptance

- cited in PubMed and archived on PubMed Central

- yours - you keep the copyright 